\title{
MANANOLIGOSSACARÍDEOS, ÁCIDOSORGÂNICOS E PROBIÓTICOS PARA LEITÕES DE 21 A 49 DIAS DE IDADE
}

\author{
MANNANOLIGOSACCHARIDES, ORGANIC ACIDS AND PROBIOTICS \\ FOR PIGLETS FROM 21 TO 49 DAYS OF AGE
}

\author{
Corassa, A. ${ }^{1 *}$, Lopes, D.C. ${ }^{2}$ e Bellaver, C. ${ }^{3}$ \\ 'Universidade Federal de Mato Grosso. Campus Universitário de Sinop. Sinop-MT. Brasil. \\ *anderson_corassa@ufmt.br \\ 2Universidade Federal de Viçosa. Campus Universitário. Viçosa-MG. Brasil. clementino@ufv.br \\ ${ }^{3}$ Embrapa Suínos e Aves. Concórdia-SC. Brasil. bellaver@qualyfoco.com.br
}

\section{Palavras chave adicionais}

Aditivos. Antimicrobianos. Desempenho. Diarréia. $\mathrm{pH}$ gastrointestinal.

\section{RESUMO}

Foi conduzido experimento utilizando 200 leitões de 21 a 49 dias de idade sob desafio sanitário, objetivando-se investigar os efeitos de dietas com mananoligossacarídeos, ácidos orgânicos e probióticos sobre o desempenho, $\mathrm{pH}$ gastrointestinal e escore de fezes. Utilizou-se o delineamento experimental de blocos ao acaso com cinco tratamentos, dez repetições e quatro animais por unidade experimental. Os tratamentos foram constituídos por dietas sem aditivos; com mananoligossacarídeos; com acidificante e probiótico; com mananoligossacarídeos, acidificante e probiótico e com antimicrobianos. De 21 a 35 dias os animais do tratamento sem aditivos apresentaram maior consumo de ração, enquanto aqueles alimentados com acidificante e probiótico apresentaram menor ganho de peso. Nos períodos de 36 a 49 dias e total observou-se maior ganho de peso para dietas com antimicrobiano em relação à dieta sem aditivos e com acidificante e probiótico. Os animais da dieta sem aditivos apresentaram pior conversão alimentar no período total. Os escores de fezes e os valores de $\mathrm{pH}$ não foram influenciados pelos tratamentos. Dietas suplementadas com mananoligossacarídeos ou com mananoligossacarídeos, acidificante e probiótico propiciaram desempenho semelhante àquelas com antimicrobianos para leitões de 21 a 49 dias de idade.

\section{AdDitiOnAL KEYWORDS}

Additives. Antimicrobials. Diarrhea. Gastrointestinal $\mathrm{pH}$. Performance.

\section{SUMMARY}

An experiment was conduced using two hundred piglets maintained from twenty one to forty nine days of age under sanitary challenge, to know effects of mannan oligosaccharides, organic acids and probiotics about performance, gastrointestinal $\mathrm{pH}$ and feces score. An experimental design of randomized blocks with five treatments, ten replicates and four animals by experimental unity was used. The treatments were constituted by diet without additive, diet with mannan oligosaccharides, diet with acidifier and probiotic, diet with combination of mannan oligosaccharides, acidifier and probiotic and diet with antimicrobials. In the period from 21 to 35 days the animals fed the diet without additive presented larger feed intake, while those fed diet with acidifier and probiotic presented smaller weight gain. In the periods from 36 to 49 days and total larger weight gain for piglets with antimicrobials in relation to diet without additive and acidifier and probiotic was observed. Piglets of diet without additives presented worses feed:gain relations in total period. The feces scores and $\mathrm{pH}$ values were not influenced by the treatments. Diets supplemented with mannan oligosaccharide or mannan oligosaccharide, acidifier and probiotic propitiated similar performance for pigs from twenty one to forty nine days of age fed diet with antimicrobials. 


\section{CORASSA, LOPES E BELLAVER}

\section{INTRODUÇÃO}

A suinocultura nacional apresenta-se como atividade de exploração econômica de destaque devido aos altos índices de produtividade alcançados. Os conhecimentos das exigências dos animais e dos valores nutricionais dos alimentos alavancaram as pesquisas e o progresso da nutrição animal. De forma a complementar as formulações, os aditivos ou microingredientes passaram a fazer parte das rações com a intenção de se obter uma melhora adicional no desempenho.

Dentre os aditivos, os antimicrobianos foram utilizados durante muitos anos como promotores de crescimento em dietas para suínos nas fases de pós-desmame e em crescimento no intuito de diminuir a incidência de diarréia e melhoria no desempenho animal (Partanen, 2002). No entanto, seu uso tem sido associado com a transmissão de genes de resistência de animais de produção para humanos (Berends et al., 2001), sendo que a bactérias zoonoticas podem ser potencialmente transmitida de suínos a população humana resultando em doença humana, que pode não responder eficientemente a tratamento antimicrobiano (Khanna et al., 2008; De Jong et al., 2009). Assim, surgiram contestações da opinião publica sobre o uso deste tipo de aditivo, que levaram a restrição ou cessação do uso de antimicrobianos como aditivos na alimentação animal enquanto promotor de crescimento, como o ocorrido no continente europeu com a proibição desde janeiro de 2006 (European Commission, 2003). No entanto, esta limitação no uso de antimicrobianos pode levar ao aumento do uso destes na forma terapêutica (Mevius et al., 2007). Segundo Van der Fels-Klerx et al. (2011) os fatores associados com o uso de antibióticos incluem o sistema de produção da granja, o número de animais e a densidade populacional na região da granja.

Por isso o desafio de gerar e introduzir estratégias e produtos que possam substituir os antimicrobianos, atendendo a padrões de segurança alimentar, mantendo ou aumentando os níveis de produtividade é enorme e oportuno. E neste contexto, especial atenção tem sido destinada à produtos a serem utilizados para leitões na fase pósdesmame por ser uma das fases mais criticas do sistema de produção de suínos (Corassa et al., 2007).

Neste cenário surgem como alternativa os prebióticos, probióticos e ácidos orgânicos que buscam alterar de maneira natural o status sanitário e nutricional a partir do perfil microbiano do trato intestinal do animal. Os prebióticos são definidos como ingredientes alimentares não digeríveis que beneficiam o animal por estimular seletivamente o crescimento e a atividade de uma ou poucas espécies de bactérias no intestino, melhorando a saúde do animal (Gibson e Roberfroid, 1995). Para Menten (2001) os probióticos atuam pelos mecanismos de exclusão competitiva, antagonismo direto, estímulo ao sistema imune, efeito nutricional, supressão da produção de amônia e neutralização de enterotoxinas. Por sua vez os ácidos orgânicos (ou seus sais), tem reduzido a freqüência de diarréia e melhorado o desempenho de leitões, pois expressam atividade antimicrobiana no estômago uma vez que o ácido não-ionizado se difunde através da membrana da bactéria e em seu interior, dissocia-se causando acidificação do citossol comprometimento da atividade celular e morte da bactéria (Freitas et al., 2006).

O uso e reuso de cama para animais confinados, sem a remoção de parte desta, influencia diretamente no seu bem-estar, principalmente devido ao acumulo de dejetos e umidade, o que torna o ambiente ideal para produção de bactérias e amônia (Moura et al., 2010), contribuindo para as variações na resposta animal. No entanto, raras são as pesquisas que avaliam esta condição de alojamento para leitões na fase pós-desmame. 
Este trabalho teve como objetivo investigar os efeitos do uso de mananligossaarídeos, ácidos orgânicos e probióticos sobre o desempenho, escore de fezes e $\mathrm{pH}$ do trato gastrointestinal de leitões de 21 a 49 dias de idade sob condições de desafio sanitário.

\section{MATERIALE MÉTODOS}

O experimento foi conduzido na Granja de Produção de Suínos do Centro Nacional de Pesquisa de Suínos e Aves (CNPSA) da Embrapa Concórdia-SC. Foram utilizados 200 leitões de cruzamentos de fêmeas F1 (Landrace x Large White) e machos Embrapa MS-58, desmamados aos 21 dias de idade, com peso médio de 7,04 $\pm 1,0 \mathrm{~kg}$. Os leitões foram distribuídos em delineamento experimental de blocos ao acaso com cinco tratamentos, dez repetições e quatro animais por unidade experimental. Para formação dos blocos foram adotados como critérios o peso, o sexo e o parentesco dos leitões.

Os tratamentos usados foram: T1: dieta basal (controle); T2: dieta basal suplementada com mananoligossacarídeos (MOS); T3: dieta basal suplementada com acidificante e probiótico $(\mathrm{A}+\mathrm{P})$; T4: dieta basal suplementada com a combinação de mananoligossacarídeos, acidificante e probiótico (COMB) e T5: dieta basal suplementada com os antimicrobianos avilamicina e colistina (ANT). O produto utilizado no tratamento 3 apresenta em sua composição: ácido cítrico, ácido sórbico, Lactobacillus acidophilus ( $\left.1 \times 10^{5} \mathrm{UFC} / \mathrm{g}\right)$, Streptococcus faecium ( $\left.1 \times 10^{5} \mathrm{UFC} / \mathrm{g}\right)$, e Bacillus subtilis. As dietas experimentais foram formuladas para atender às exigências nutricionais mínimas recomendadas por Rostagno et al. (2000), e foram compostas para duas fases: pré-inicial I para o período de 21 a 35 dias e pré-inicial II para o período de 36 a 49 dias de idade dos leitões (tabela I).

Os aditivos foram adicionados às dietas em substituição ao caulim nas seguintes concentrações: 4 e $2 \mathrm{~kg} . \mathrm{t}^{-1}$ de MOS para as
Tabela I. Composição (\%) das rações experimentais das fases pré-inicial I (21 a 35 dias) e pré-inicial II (36 a 49 dias). (Composition (\%) of experimental rations of pre-initial I (21 at 35 days) and pre-initial II (36 at 49 days) stages).

\begin{tabular}{|c|c|c|}
\hline & \multicolumn{2}{|c|}{ Dietas basais } \\
\hline & $21-35$ & $36-49$ \\
\hline Milho pré-gelatinizado & 20,00 & 10,00 \\
\hline Farelo de soja & 18,00 & 18,00 \\
\hline Proteína texturizada de soja & 17,60 & 14,50 \\
\hline Milho grão & 11,80 & 38,50 \\
\hline Lactose & 8,50 & 2,50 \\
\hline Óleo de soja & 5,30 & 3,30 \\
\hline Soro de leite & 5,00 & 5,00 \\
\hline Farinha de trigo & 5,00 & - \\
\hline Açúcar & 3,00 & 3,00 \\
\hline Fosfato mono-bicálcico & 1,896 & 1,525 \\
\hline Calcário & 0,932 & 1,114 \\
\hline Caulim & 0,948 & 0,778 \\
\hline Sal & 0,424 & 0,367 \\
\hline Adsorvente & 0,300 & 0,300 \\
\hline DL-Metionina & 0,252 & 0,186 \\
\hline L-Lisina & 0,244 & 0,197 \\
\hline L-Treonina & 0,224 & 0,167 \\
\hline Suplemento vitamínico ${ }^{1}$ & 0,200 & 0,200 \\
\hline Suplemento mineral ${ }^{2}$ & 0,148 & 0,150 \\
\hline Cloreto de colina $(60 \%)$ & 0,131 & 0,126 \\
\hline Aromatizante & 0,050 & 0,050 \\
\hline L-Triptofano & 0,036 & 0,025 \\
\hline Antioxidante BHT & 0,015 & 0,015 \\
\hline Total & 100,00 & 100,00 \\
\hline \multicolumn{3}{|c|}{ Composição nutricional calculada } \\
\hline Proteína bruta \% & 21,00 & 20,00 \\
\hline Energia met. (kcal/kg) & 3500 & 3500 \\
\hline $\mathrm{Ca}(\%)$ & 0,85 & 0,83 \\
\hline $\mathrm{P}$ total $(\%)$ & 0,72 & 0,67 \\
\hline P disponível (\%) & 0,50 & 0,43 \\
\hline $\mathrm{Na}(\%)$ & 0,22 & 0,20 \\
\hline Lisina digestível (\%) & 1,23 & 1,12 \\
\hline Met + Cist dig. (\%) & 0,74 & 0,68 \\
\hline Treonina dig. (\%) & 0,80 & 0,74 \\
\hline Triptofano dig. (\%) & 0,23 & 0,21 \\
\hline Lactose (\%) & 12,00 & 6,00 \\
\hline
\end{tabular}

${ }^{1}$ Conteúdo/kg de ração: vit. A: 6000 UI; vit. $D_{3}: 1500$ UI; vit. E: 15 UI; vit. $\mathrm{K}_{3}: 1,5 \mathrm{mg}$; vit. $\mathrm{B}_{1}: 1,35 \mathrm{mg}$; vit. $\mathrm{B}_{2}: 4 \mathrm{mg}$; vit. $\mathrm{B}_{6}: 2 \mathrm{mg}$; vit. $\mathrm{B}_{12}: 20 \mathrm{mcg}$; ácido fólico: $0,6 \mathrm{mg}$;ácido nicotínico: $20 \mathrm{mg}$; ácido pantatênico: 9,35 mg; biotina: 0,8 mg; Se: 0,300 mg. ${ }^{2}$ Conteúdo/ $\mathrm{kg}$ de ração: $\mathrm{Fe}: 100 \mathrm{mg}$; $\mathrm{Cu}: 10 \mathrm{mg}$; $\mathrm{Co:} 1 \mathrm{mg}$; $\mathrm{Mn}$ : 40 mg; Zn: 100 mg; I: 1,5 mg. 
fases pré-inicial I e II, respectivamente; 5 $\mathrm{kg} . \mathrm{t}^{-1}$ de acidificante e probiótico; $400 \mathrm{~g} . \mathrm{t}^{-1}$ de sulfato de colistina e 200 g. $\mathrm{t}^{-1}$ de avilamicina. As rações foram produzidas em forma física farelada na fábrica de rações do CNPSA.

Os leitões recém-desmamados foram alojados em salas de creche de alvenaria com baias ao chão, piso de cimento e cama de maravalha reutilizada para caracterizar o desafio sanitário. No dia antecedente à distribuição dos animais, a cama pertencente ao lote de leitões anterior foi retirada das creches, homogeneizada, acrescida de maravalha nova e redistribuída uniformemente nas baias para padronização do desafio.

Para avaliação do desempenho foram utilizadas as variáveis: consumo de ração médio diário (CRMD), ganho de peso médio diário (GPMD) e conversão alimentar (CA). Para mensuração destes dados foram realizadas pesagens quinzenais dos animais e dos comedouros. Os dados foram analisados nos períodos 21 a 35,36 a 49 e 21 a 49 dias de idade dos leitões.

Diariamente avaliou-se a consistência das fezes, utilizando-se o seguinte escore: 1-fezes duras e firmes; 2-fezes de consistência normal; 3-fezes pastosas, não diarréicas; 4-fezes aquosas, características de sintoma diarréico. A avaliação foi feita por um único observador atribuído-se um escore para cada unidade experimental. Os valores referentes aos dois primeiros dias de experimento foram excluídos da análise devido a ausência de fezes na maioria das unidades experimentais.

No $28^{\circ}$ e $35^{\circ}$ dias de idade dos leitões, quatro animais por tratamento foram abatidos para leitura de $\mathrm{pH}$ no estômago e no duodeno. Foram escolhidos animais com peso mais próximo da média da unidade experimental. Os animais foram levados à sala de necrópsias do setor de Sanidade Animal do CNPSA, onde foram dessensibilizados por descarga elétrica de 220 volts e sangrados imediatamente. Em seguida as vísceras foram removidas e se procedeu a realizar as leituras $\mathrm{pH}$ utilizando-se um medidor de $\mathrm{pH}$ portátil. O estômago foi pinçado na região pilórica e uma incisão de $4 \mathrm{~cm}$ foi realizada para introdução do sensor para a primeira leitura de $\mathrm{pH}$. No duodeno, a leitura foi tomada junto à flexura duodeno-jejunal, à aproximadamente $15 \mathrm{~cm}$ da primeira leitura.

Os dados de desempenho e $\mathrm{pH}$ de estômago e duodeno foram submetidos à análise de variância com as médias comparadas pelo teste de Student-Newman-Keuls e para análise de escore de fezes utilizou-se o teste não paramétrico de Kruskal-Wallis, ambos ao nível de 5\% de probabilidade, utilizando-se o programa SAEG (UFV, 2007).

\section{RESULTADOSEDISCUSSÃO}

O consumo de ração foi influenciado $(\mathrm{p}<0,05)$ pelos tratamentos no período de 21 a 35 dias, onde se observou maiores valores dos animais que receberam dieta sem aditivos em comparação a todas as demais (tabela II). Nos períodos de 36 a 49 e 21 a 49 dias, o consumo de ração não variou $(\mathrm{p}>0,05)$ entre os tratamentos. A similaridade de consumo entre a dieta controle e contendo MOS também foi observada por Santos et al. (2003) ao incluir até $0,2 \%$ de manose.

Os leitões alimentados com dietas contendo acidificante e probiótico apresentaram menor $(p<0,05)$ ganho de peso em relação aos demais tratamentos, que não diferiram entre si no primeiro período avaliado (tabela II). Estes resultados diferem daqueles apresentados por Tsiloyannis et al. (2001) que, observaram maior ganho de peso para leitões de 21 a 35 dias de idade alimentados com dieta contendo antimicrobianos em relação aos que receberam dieta sem aditivos.

O ganho de peso foi influenciado $(p>0,05)$ pelos tratamentos nos períodos de 36 a 49 e 21 a 49 dias, quando os animais recebendo dietas com antimicrobianos apresentaram maiores valores que aqueles alimentados com a dieta controle e acidificante e probiótico. Os valores de ganho de peso dos 
Tabela II. Valores de peso corporal, consumo de ração médio diário (CRMD), ganho de peso médio diário (GPMD) e conversão alimentar $(C A)$ de leitões dos 21 aos 49 dias de idade submetidos às dietas com diferentes aditivos. (Values of body weight, average daily feed intake (CRMD), average daily weight gain (GPMD) and feed:gain ratio (CA) of piglets fed diets with different additives since 21 to 49 days old).

\begin{tabular}{|c|c|c|c|c|c|c|c|}
\hline \multicolumn{8}{|c|}{ Tratamentos ${ }^{1,2}$} \\
\hline & Controle & MOS & $A+P$ & COMB & ANT & Signif. & CV (\%) \\
\hline \multicolumn{8}{|c|}{ Peso corporal (kg) } \\
\hline Inicial & 7,05 & 7,04 & 7,05 & 7,04 & 7,03 & 0,99 & 3,9 \\
\hline Final & 14,03 & 14,16 & 13,71 & 14,15 & 15,07 & 0,39 & 9,4 \\
\hline \multicolumn{8}{|l|}{ CRMD (g/dia) } \\
\hline $21-35$ dias & $223^{a}$ & $172^{\mathrm{b}}$ & $163^{b}$ & $178^{b}$ & $172^{\mathrm{b}}$ & 0,00 & 15,3 \\
\hline $36-49$ dias & 644 & 623 & 619 & 605 & 670 & 0,37 & 12,1 \\
\hline 21-49 dias & 434 & 398 & 391 & 392 & 421 & 0,12 & 10,7 \\
\hline \multicolumn{8}{|l|}{ GPMD (g/dia) } \\
\hline $21-35$ dias & $78^{\mathrm{a}}$ & $79^{a}$ & $59^{b}$ & $76^{a}$ & $87^{a}$ & 0,00 & 18,5 \\
\hline 36-49 dias & $421^{b}$ & $430^{\mathrm{ab}}$ & $417^{b}$ & $432^{a b}$ & $488^{a}$ & 0,04 & 12,1 \\
\hline 21-49 dias & $249^{b}$ & $255^{\mathrm{ab}}$ & $238^{b}$ & $254^{\mathrm{ab}}$ & $287^{a}$ & 0,02 & 12,0 \\
\hline \multicolumn{8}{|l|}{ CA $(g / g)$} \\
\hline 21-35 dias & $2,85^{b}$ & $2,23^{a}$ & $2,97^{b}$ & $2,42^{\mathrm{a}}$ & $2,03^{a}$ & 0,00 & 17,0 \\
\hline $36-49$ dias & $1,55^{\mathrm{b}}$ & $1,45^{\mathrm{ab}}$ & $1,49^{\mathrm{ab}}$ & $1,41^{\mathrm{ab}}$ & $1,38^{a}$ & 0,02 & 7,6 \\
\hline 21-49 dias & $1,75^{\mathrm{C}}$ & $1,56^{\mathrm{ab}}$ & $1,65^{b}$ & $1,55^{\mathrm{ab}}$ & $1,47^{\mathrm{a}}$ & 0,00 & 6,6 \\
\hline
\end{tabular}

${ }^{1}$ Controle: dieta sem aditivos; MOS: dieta com mananoligossacarídeos; $\mathrm{A}+\mathrm{P}$ : dieta contendo acidificante e probiótico; COMB: dieta contendo combinação de mananoligossacarideos, acidificante e probiótico; ANT: dieta contendo antimicrobianos avilamicina e colistina; CV: coeficiente de variação.

${ }^{2}$ Médias seguidas de letras diferentes na mesma linha diferem estatisticamente pelo teste de Student Newman Keuls ao nível de $5 \%$ de probabilidade.

animais que receberam os tratamentos MOS e a combinação de mananoligossacarídeos, acidificante e probiótico foram semelhantes $(p>0,05)$ entre si e não variaram em relação aos animais que receberam os demais tratamentos. Efeitos semelhantes em leitões de 21 a 49 dias de idade foram observados por Tsiloyiannis et al. (2001), que observaram melhores valores de ganho de peso e conversão alimentar em animais alimentados com antimicrobianos, comparados ao ácido cítrico e que por sua vez foram melhores que a dieta controle. Os resultados deste trabalho corroboram com outros apresentados na literatura como os de Pettigrew (2000) que, compilando dezessete trabalhos investigativos constatou respostas positivas em ganho de peso e conversão alimen- tar, embora estatisticamente não significativas, para adição de MOS.

Para o período de 21 a 35 dias observouse melhor $(p<0,05)$ conversão alimentar dos leitões que receberam os tratamentos com antimicrobianos, MOS e COMB em relação aos demais tratamentos (tabela II). No período de 36 a 49 dias, apenas os animais submetidos à dieta com antimicrobianos apresentaram melhor conversão alimentar $(\mathrm{p}<0,05)$ em relação à dieta controle, com os demais tratamentos não diferindo entre si. Estes resultados foram semelhantes aos obtidos por Santos et al. (2002) e Utiyama et al. (2006) que não observaram diferença de desempenho entre dietas com promotor de crescimento e MOS para leitões, bem como Omogbenigun et al. (2003), que 
observaram eficiência alimentar de leitões alimentados com dietas com ácidos orgânicos não diferente daqueles alimentados com dieta controle.

Avaliando-se o período total do experimento, observou-se que os animais submetidos a dieta controle apresentaram pior $(\mathrm{p}<0,05)$ conversão alimentar em relação aos que receberam os demais tratamentos. $\mathrm{O}$ tratamento com antimicrobianos não apresentou diferença $(p>0,05)$ com os tratamentos MOS e a combinação de mananoligossacarídeos, acidificante e probiótico, mas foi superior ao tratamento contendo acidificante e probiótico. Estas diferenças estão de acordo com Davis et al. (2002) que observaram melhora significativa da conversão alimentar e ganho de peso quando compararam dietas suplementadas com MOS contra uma dieta controle para leitões até 28 dias após o desmame. Diferentemente de Teixeira et al. (2003) que, avaliaram o efeito de diferentes acidificantes e suas combinações em dietas leitões de 21 a 60 dias de idade, e não observaram melhora em termos de conversão alimentar e consumo, embora tenham constatado diferenças de ganho de peso quando comparados ao controle. Os resultados deste trabalho também apresentam-se distintos dos publicados por Braz et al. (2011) que, observaram melhor conversão alimentar de leitões desmamados alimentados com dietas contendo uma combinação de acidificantes em relação a dieta contendo antimicrobiano.

Baseando-se na equivalência de consumo entre os tratamentos, constatou-se a melhor eficiência de utilização de nutrientes dos animais alimentados com dietas contendo antimicrobianos, MOS e a combinação de mananoligossacarídeos, acidificante e probiótico. Esta resposta pode estar relacionada à sinergia potencial entre probióticos e acidificantes feitos à base de ácidos orgânicos, dado que os ácidos favorecem o crescimento do probiótico, que irá produzir mais ácidos orgânicos voláteis que inibem o crescimento de bactérias potencialmente patogênicas e assim mantém o estado de equilíbrio a favor da flora benéfica (Silva Júnior, 2009). Porém, ficou caracterizado neste trabalho que as condições de desafio sanitário impostas restringiram o crescimento dos animais e que os aditivos avaliados auxiliaram no combate a agentes patogênicos, todavia a resposta dos produtos não foi potencializada. Esta constatação difere dos achados de Rozeboom et al. (2005) ao compararem os efeitos de MOS e antimicrobianos no desempenho de leitões alojados sob diferentes granjas que expressavam diferentes desafios à saúde dos animais cuja conclusão foi de que MOS poderia ser uma alternativa como promotor de crescimento. No entanto, Chiquieri et al. (2006) não constatarem diferença no consumo de ração, ganho de peso e conversão alimentar de machos castrados alimentados com antimicrobiano, probiótico, prebiótico ou combinação de prebiótico e probiótico.

Observou-se que os resultados de desempenho obtidos pelos animais alimentados com dietas contendo antimicrobianos, foram estatisticamente superiores àqueles da dieta controle, o que poderia sugerir a hipótese de que a cama reutilizada neste experimento expressa maior grau de desafio sanitário em relação a outros trabalhos de investigação do uso desses aditivos. Estes resultados estão de acordo com os de Chiquieri et al. (2009) que observaram maior ganho de peso dos animais alimentados com ração contendo antibiótico em relação a ração sem adição de pró-nutrientes em dietas para leitões no período de 21 a 63 dias de idade. Para Santos et al. (2010), ao avaliar trabalhos em que não se observaram efeitos de MOS sobre o desempenho, poderia indicar falta de desafio sanitário nas instalações onde são conduzidos os experimentos ou a necessidade de mais conhecimento sobre a quantidade exata de prebiótico a ser incluída nas rações.

Os tratamentos não influenciaram ( $p>0,05)$ o escore de fezes em nenhum dos períodos analisados (tabela III). O número 
de observações no escore 4, que caracteriza diarréia, se mostrou elevado em todos os tratamentos, contudo, havendo diminuição destes ao compararmos o primeiro e o segundo período analisados. Estes resultados diferem dos obtidos por Tsiloyiannis et al. (2001) e Owusu-Asiedu et al. (2003) que observaram menores escores de fezes em leitões alimentados com antimicrobianos ou com acidificantes em relação à dieta controle. Por outro lado, os estudos de Utiyama et al. (2006), Santos et al. (2010) e Braz et al. (2011) não identificaram efeito de mananoligossacarídeos, probióticos, acidificantes e antimicrobianos sobre a frequiência de diarréia, corroborando com este trabalho.

Os valores de $\mathrm{pH}$ do bolo alimentar no estômago e da digesta no duodeno não foram influenciados $(\mathrm{p}>0,05)$ pelos trata- mentos (tabela IV). A amplitude dos valores de $\mathrm{pH}$ estomacal dos leitões aos 28 dias apresenta-se abaixo daquela encontrada por Santos et al. (2003) com animais de 60 dias, que oscilou de 3,4 a 3,8. Valores de $\mathrm{pH}$ maiores no duodeno em relação ao estômago também foram observados por Adams (2000) que constatou a tendência do aumento do $\mathrm{pH}$ ao longo do comprimento do trato gastrointestinal chegando a neutro no reto.

Os resultados de $\mathrm{pH}$ no trato gastrointestinal deste trabalho corroboram com os de Freitas et al. (2006) que encontraram valores entre 3,60 e 3,79 para o estomago de leitões entre 21 e 35 dias de idades, mas não obteve efeitos de diferentes níveis de ácido lático, assim como Omogbenigun et al. (2003) que não encontraram efeito de ácidos orgânicos sobre o $\mathrm{pH}$ da digesta do

Tabela III. Número de observações de escores de fezes de leitões dos 21 aos 49 dias de idade que consumiram dietas com diferentes aditivos. (Distribution of observations of feces consistence for weaners from 21 to 49 days of age that consumed diets with different additive).

\begin{tabular}{lccccccc}
\hline Fezes & Controle & MOS & $\begin{array}{c}\text { Tratamentos }^{1} \\
\text { A+P }\end{array}$ & COMB & ANT & Total & $\%$ \\
\hline 21-35 dias & & & & & & & \\
Escore 1 & 0 & 2 & 0 & 0 & 3 & 5 & 0,83 \\
Escore 2 & 4 & 10 & 9 & 14 & 10 & 47 & 7,83 \\
Escore 3 & 34 & 25 & 32 & 41 & 39 & 171 & 28,51 \\
Escore 4 & 82 & 83 & 79 & 65 & 68 & 377 & 62,83 \\
Total & 120 & 120 & 120 & 120 & 120 & 600 & \\
36-49 dias & & & & & & & \\
Escore 1 & 0 & 0 & 0 & 0 & 0 & 0 & 0 \\
Escore 2 & 31 & 40 & 38 & 46 & 52 & 207 & 29,57 \\
Escore 3 & 82 & 66 & 65 & 69 & 55 & 337 & 48,14 \\
Escore 4 & 27 & 34 & 37 & 25 & 33 & 156 & 22,29 \\
Total & 140 & 140 & 140 & 140 & 140 & 700 & \\
21-49 dias & & & & & & & \\
Escore 1 & 0 & 2 & 0 & 0 & 3 & 5 & 0,38 \\
Escore 2 & 35 & 50 & 47 & 60 & 62 & 254 & 19,54 \\
Escore 3 & 116 & 91 & 97 & 110 & 94 & 508 & 39,08 \\
Escore 4 & 109 & 117 & 116 & 90 & 101 & 533 & 41,00 \\
Total & 260 & 260 & 260 & 260 & 260 & 1300 & \\
\hline
\end{tabular}

${ }^{1}$ Controle: dieta sem aditivos; MOS: dieta com mananoligossacarídeos; $\mathrm{A}+\mathrm{P}$ : dieta contendo acidificante e probiótico; COMB: dieta contendo combinação de mananoligossacarideos, acidificante e probiótico; ANT: dieta contendo antimicrobianos avilamicina e colistina. 
CORASSA, LOPES E BELLAVER

Tabela IV. Valores de pH do estômago e duodeno de leitões abatidos aos 28 e 35 dias de idade submetidos às dietas com diferentes aditivos. (Values for stomach and duodenum's pH of piglets submeted experimental diets slaughtered at 28 and 35 days old).

\begin{tabular}{|c|c|c|c|c|c|c|c|c|}
\hline \multirow[b]{2}{*}{ Variáveis } & \multicolumn{5}{|c|}{ Tratamentos $^{1}$} & \multirow[b]{2}{*}{ Média } & \multirow[b]{2}{*}{ Signif. } & \multirow[b]{2}{*}{ CV (\%) } \\
\hline & Controle & MOS & $A+P$ & COMB & ANT & & & \\
\hline \multicolumn{9}{|l|}{ Estômago } \\
\hline 28 dias & 3,39 & 3,23 & 2,64 & 2,83 & 3,18 & 3,05 & 0,26 & 16,1 \\
\hline 35 dias & 3,18 & 3,60 & 3,33 & 3,75 & 2,75 & 3,32 & 0,18 & 16,5 \\
\hline \multicolumn{9}{|l|}{ Duodeno } \\
\hline 28 dias & 5,34 & 5,59 & 5,79 & 5,94 & 6,05 & 5,74 & 0,08 & 5,9 \\
\hline 35 dias & 5,62 & 5,73 & 5,74 & 5,81 & 5,24 & 5,63 & 0,42 & 7,8 \\
\hline
\end{tabular}

estômago e íleo. No mesmo sentido Braz et al. (2011) não encontraram efeito de acidificantes e antimicrobianos sobre o $\mathrm{pH}$ estomacal, no entanto, certa combinação de acidificantes apresentou redução de $\mathrm{pH}$ cecal em relação a animais com dietas contendo antimicrobianos. Entretanto os dados deste trabalho diferem dos apresentados por Owusu-Asiedu et al. (2003) que observaram redução de $\mathrm{pH}$ do estômago de leitões alimentados com antimicrobianos e outros aditivos em comparação a dieta controle, contudo não apresentaram efeitos ao nível de intestino delgado. Este autor ainda enfatiza que valores elevados de $\mathrm{pH}$ gástrico em leitões podem ser associados ao aumento da proliferação de $E$. coli enterotóxica e este fato resulta na incidência de diarréia e aumento da mortalidade.

A partir dos valores obtidos ficou caracterizado que os tratamentos propostos não foram efetivos na redução do $\mathrm{pH}$ do duodeno para valores que limitassem o desenvolvimento de bactérias patogênicas, os quais segundo Blanchard (2000), devem estar fora da faixa de 4,3 a 9,5 para E. coli, e 4,0 a 9,0 para Salmonella sp. Segundo Gauthier (2003) a inclusão de ácidos e sais orgânicos entre 1 e $2 \%$ na ração pode reduzir o pH estomacal, diminuir a proliferação de microorganismos patogênicos no trato digestivo, melhorar o ganho de peso diário e a conversão alimentar dos leitões, embora muitos estudos mostram que é praticamente impossível modificar, significativamente o pH do estômago e intestino de um suíno, mesmo quando se utilizam grandes quantidades de ácidos orgânicos nas rações.

\section{CONCLUSÕES}

Dietas suplementadas com mananoligossacarídeos ou combinação de mananoligossacarídeos com acidificante e probiótico propiciam desempenho semelhante a dietas suplementadas com colistina e avilamicina para leitões de 21 a 49 dias de idade em condições de desafio sanitário.

Leitões de 21 a 49 dias de idade em condições de desafio sanitário alimentados com dietas contendo mananoligossacarídeos, acidificante e probiótico e sua combinação apresentam melhor conversão alimentar que aqueles alimentados com dieta sem aditivos.

Mananoligossacarídeos, acidificante e probiótico, sua combinação e antibióticos não influenciam o pH gástrico e intestinal bem como o escore de fezes de leitões de 21 a 49 dias de idade em condições de desafio sanitário. 


\section{MANANOLIGOSSACARÍDEOS, ÁCIDOS ORGÂNICOSE PROBIÓTICOS PARALEITÕES}

\section{AGRADECIMENTOS}

À Alltech do Brasil Agroindustrial Ltda, pelo apoio financeiro da pesquisa. À Coordenação de Aperfeiçoamento de Pessoal de Nível Superior (CAPES) pela concessão de

\section{BIBLIOGRAFIA}

Adams, A.C. 2000. Acidifiers: important components of pig feeds. Technical Information. Kemin Industries (Asia). Singapore. pp.1-6.

Berends, B.R., Van den Bogaard, A.E.J.M., Van Knapen, F. and Snijders, J.M.A. 2001. Human health hazards associated with the administration of antimicrobials to slaughter animals. Vet Quart, 23: 10-21.

Blanchard, P. 2000. Less buffering... more enzymes and organic acids. Pig Progr, 16: 2325.

Braz, D.B., Costa, L.B., Berenchtein, B., Tse, M.L.P., Almeida, V.V. e Miyada, V.S. 2011. Acidificantes como alternativa aos antimicrobianos promotores do crescimento de leitões. Arch Zootec, 60: 745-756.

Chiquieri, J.M.S., Soares, R.T.R.N., Lyra, M.S., Hurtado Nery, V.L. e Fonseca, J.B. 2009. Ácidos orgânicos na alimentação de leitões desmamados. Arch Zootec, 58: 609-612.

Chiquieri, J.M.S., Soares, R.T.R.N., Souza, J.C.D., Hurtado Nery, V.L., Ferreira, R.A. e Ventura, B.G. 2006. Probiótico y prebiótico en la alimentación de cerdos en crecimiento y terminación. Arch Zootec, 55: 305-308.

Corassa, A., Lopes, D.C., Pena, S.M., Freitas, L.S. e Pena, G.M. 2007. Hidrolisado de mucosa intestinal de suínos em substituição ao plasma sangüíneo em dietas para leitões de 21 a 49 dias. Rev Bras Zootecn, 36 (Supl.): 2029-2036.

Davis, M.E., Maxwell, C.V., Brown, D.C., Erfand, G.F. and Wistuba, T.J. 2002. The effect of mannan oligosaccharide on growth and immune responses of weaning piglets. Annual Meeting of the American Society of Animal Sciences. Quebec. Canada.

De Jong, A., Bywater, R., Butty, P., Deroover, E., Godinho, K., Klein, U., Marion, H., Simjee, S., Smets, K., Thomas, V., Valle, M. and Wheadon, A. 2009. A pan-European survey of antimicrobial susceptibility towards human-use antimicrobial drugs among zoonotic and commensal enteric bolsa de mestrado do primeiro autor. Ao Centro Nacional de Pesquisa de Suínos e Aves (CNPSA) da Empresa Brasileira de Pesquisa Agropecuária (Embrapa) pelo apoio na execução da pesquisa.

bacteria isolated from healthy food-producing animals. J Antimicrob Chemoth, 63: 733-744.

European Commision. 2003. Regulation (EC) № $1831 / 2003$ of the European Parliament and of the Council of 22 September 2003 on additives for use in animal nutrition. Official Journal of the European Communities, L268: 29-43.

Freitas, L.S., Lopes, D.C., Freitas, A.F., Carneiro, J.C., Corassa, A., Pena, S.M. e Costa, L.F. 2006. Avaliação de ácidos orgânicos em dietas para leitões de 21 a 49 dias de idade. Rev Bras Zootecn, 35: 1711-1719.

Gauthier, R. 2003. Avanços atuais em suinocultura. Pork Word. 3: 98-102.

Gibson, G.R. and Roberfroid, M.B. 1995. Dietary modulation of the human colonic microbiota: introducing the concept of prebiotics. J Nutr, 125: 1401-1412.

Khanna, T., Friendship, R., Dewey, C. and Weese, J.S. 2008. Methicillin resistant Staphylococcus aureus colonization in pigs and pig farmers. Vet Microbiol, 128: 298-303.

Menten, J.F.M. 2001. Aditivos alternativos na nutrição de aves: probióticos e prebióticos. Reunião Anual da Sociedade Brasileira de Zootecnia, 38. Anais...Piracicaba. pp.141-157.

Mevius, D.M., Wit, B. and Van Pelt, W. (Eds.). 2007. MARAN-2007. Monitoring of antimicrobial resistance and antibiotic usage in animals in the Netherlands in 2006/2007. Ed. VANTURES. The Veterinary antibiotic Usage and Resistance Surveillance Working Group. Central Veterinary Institute. Wageningen UR. Lelystad. The Netherlands. www.cvi.wur.nl/UK/publications/ outherpublications/maran (01/04/2010).

Moura, D.J., Bueno, L.G.F., Lima, L.A.O., Carvalho, T.M.R. and Maia, A.P.A. 2010. Strategies and facilities in order to improve animal welfare. Rev Bras Zootecn, 39: 311-316.

Omogbenigun, F.O., Nyachoti, C.M. and Slominski, B.A. 2003. The effect of supplementing microbial phytase and organic acids to a corn-soybean 


\section{CORASSA, LOPES E BELLAVER}

based diet fed to early-weaned pigs. J Anim Sci, 81: 1806-813.

Owusu-Asiedu, A., Nyachoti, C.M. and Marquardt, R.R. 2003. Response of early-weaned pigs to an enterotoxigenic Escherichia coli (K88) challenge when fed diets containing spraydried porcine plasma or pea protein isolate plus egg yolk antibody, zinc oxide, fumaric acid, or antibiotic. J Anim Sci, 81: 1790-1798.

Partanen, K. 2002. Uso de aditivos na produção de suínos. Simpósio sobre Manejo e Nutrição de Aves e Suínos e Tecnologiana Produção de Rações. Anais... Colégio Brasileiro de Nutrição Animal. Campinas. pp. 45-62.

Pettigrew, J.E. 2000. Bio-Mos effects on pig performance: a review. Alltech's $16^{\text {th }}$ Annual Symposium. Proceedings... Nottingham University Press. Nottingham, UK. pp. 31-44.

Rostagno, H.S., Albino, L.F.T., Donzele, J.L., Gomes, P.C., Oliveira, R.F., Lopes, D.C., Ferreira, A.S. e Barreto, S.L.T. 2000. Composição de alimentos e exigências nutricionais de aves e suínos, tabelas brasileiras. Universidade Federal de Viçosa. Viçosa, MG. 141 pp.

Rozeboom, D.W., Shaw, D.T., Tempelman, R.J., Miguel, J.C., Pettigrew, J.E. and Connolly, A. 2005. Effects of mannan oligosaccharide and an antimicrobial product in nursery diets on performance of pigs reared on three different farms. J Anim Sci, 83: 2637-2644.

Santos, M.S., Bauermann, I., Decker, S., Lima, S.A., Sestak, D., Pozza, P.C., Pereira, E.S. e Arruda, A.M.V. 2002. Desempenho de leitões suplementados com mananoligossacarídeos. XXXIX Reunião Anual da SBZ. Anais... SBZ. Recife, PE. CD-ROM.

Santos, V.M., Thomaz, M.C., Pascoal, L.A.F., Ruiz, U.S., Watanabe, P.H., Huaynate, R.A.R., Silva, S.Z. e Faria, H.G. 2010. Digestibilidade, desempenho e características morfofisiológicas do trato digestório de leitões desmamados sob dietas com mananoligossacarídeo. Pesqui Agropecu Bras, 45: 99-105.

Santos, W.G., Filgueiras, E.P., Bertechini, A.G., Fialho, E.T., Lima, J.A.F. e Brito, M.A.V.P. 2003. Manose na alimentação de leitões na fase de creche (desempenho, $\mathrm{pH}$ de do trato gastrintestinal e peso dos órgãos). Ciên Agrotec, 27: 696-702.

Silva Junior, A. 2009. Interações químicofisiolóficas entre acidificantes, probióticos, enzimas e lisofosfolipídios na digestão de leitões Rev Bras Zootecn, 38: 238-245.

Teixeira, M.P., Silva, G.F., Lopes, D.C., Corassa, A., Teixeira, A.O., Bunzen, S., Pena, S.M., Gattas, G. e Costa, L.F. 2003. Avaliação de ácidos orgânicos e inorgânicos em dietas para leitões desmamados aos 21 dias de idade. 40 ${ }^{\mathrm{a}}$ Reunião Anual da SBZ. Anais...SBZ. Santa Maria, RS.

Tsiloyiannis, V.K., Kyriakis, S.C., Vlemmas, J. and Sarris, K. 2001. The effect of organic acids on the control of porcine post-weaning diarrhea. Res Vet Sci, 70: 287-293.

UFV. 2007. Universidade Federal de Viçosa. Sistema para análises estatísticas e genética SAEG. (Versão 9.1). Universidade Federal de Viçosa. Viçosa-MG. 149 pp.

Utiyama, C.E., Oetting, L.L., Giani, P.A., Ruiz, U.S. e Miyada, V.S. 2006. Efeitos de antimicrobianos, prebióticos, probióticos e extratos vegetais sobre a microbiota intestinal, a freqüência de diarréia e o desempenho de leitões recém-desmamados. Rev Bras Zootecn, 35: 2359-2367.

Van der Fels-Klerx, H.J., Puister-Jansen, L.F., Van Asselt, E.D. and Burgers, S.L.G.E. 2011. Farm factors associated with the use of antibiotics in pig production. J Anim Sci, 89: 1922-1929. 